
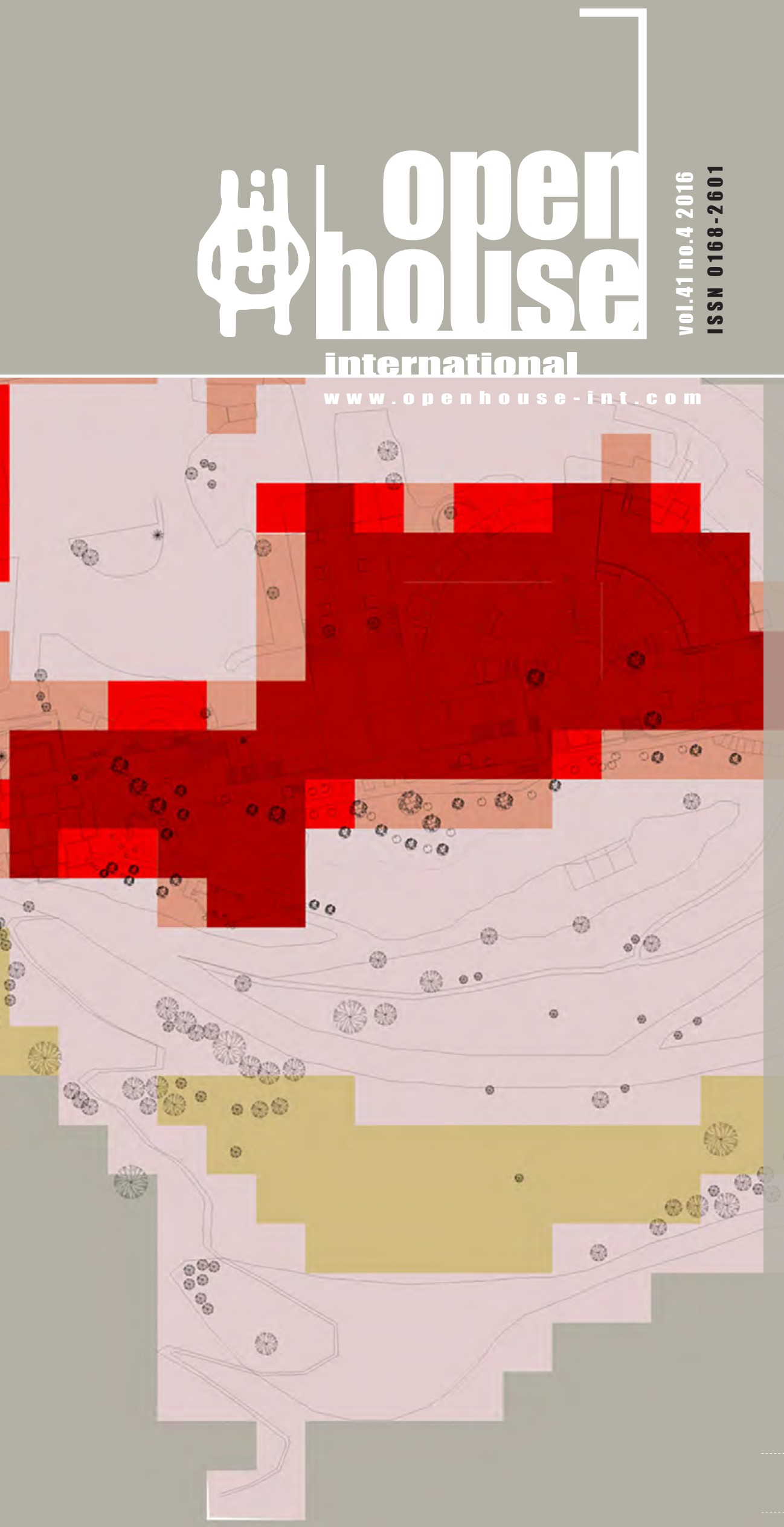

ThPMPRESTR:

FORGING ADUANGES IN SUSTAINABLE ARGHTEQTURE AND URBANISW

D Bsign for Bhang

Greg I U ba I is m

BuIf Bitios

Space / Nature Syntax

The Urban Laboratory

Traditional hasterplanning

Susta inable Urban Dovelopme in t

Urban Texture

Authors In this issue:

Aydın, Bagaeen, Barbour, Feliciotti, Grierson,

Ibrahim, Munro, Porta, Rae, Romice, Salama,

Wiedmann.

6

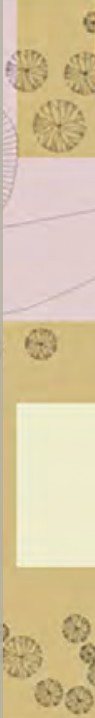

Elsevier Scopus

Thomson ISI Arts \& Humanities

EBSEO publishing

a HIB eneouraged journal 


\title{
TOWARDS THE DEVELOPMENT OF A SPACE/NATURE SYNTAX AT ARCOSANTI.
}

\section{Karen Munro, David Grierson}

\begin{abstract}
The world's urban population is rapidly growing, now exceeding its rural population, and is expected to reach $70 \%$ of the world's total by 2050. Research in environmental psychology increasingly supports the Biophilia Hypothesis which holds that our connection with Nature is innate. Thus, how do we maintain a human connection to Nature in an increasingly urbanising world? This paper is based on current research work and explores the boundary between built and natural environments, specifically how visual connectivity to Nature affects how people use social spaces, compared to spatial connectivity. Case study work is being undertaken at Arcosanti urban laboratory in the Arizona desert. Arcosanti construction began in 1970 to test Paolo Soleri's Arcology Theory which proposes, in opposition to sprawling cities, a new form of urban setting which is compact with tightly restricted horizontal growth, leaving the surrounding natural environment as undeveloped "wilderness". Through development of a Space/Nature Syntax methodology applied within a uniquely compact urban form, this research attempts to understand how designing to maintain the instinctive bond with Nature can affect social interaction and inform future design choices within built environments. This paper describes the development of, and basis for, the Space/Nature Syntax methodology, presents initial findings achieved through its recent application at Arcosanti, and outlines future work. Initial analysis indicates that visual connectivity to Nature is a significant influence on certain types of social interactions when compared to spatial connectivity, although more research is needed to verify the level of significance.
\end{abstract}

Keywords: Social Spaces, Biophilia, Environmental Psychology, Space Syntax, Urbanisation, Wilderness.

\section{INTRODUCTION}

In his 1984 book "Biophilia" E.O. Wilson proposed that human beings have evolved to expect, and indeed physically need, a connection to other living species and the natural environment. He theorised that the increasing, and relatively recent, removal of human civilisation from Nature through urbanisation is detrimental to the human mind and its development. He called his theory the Biophilia Hypothesis, and presented a relationship with the natural environment as an innate need within humanity. (Grinde and Patil, 2009)

Humanity's appreciation of Nature has certainly been historically recognised and widely and consistently portrayed through media such as art and literature long before the Biophilia Hypothesis was proposed. Romanticism saw writers such as Henry David Thoreau, Lord Byron, and Ralph Waldo Emerson recognise the importance of Nature as cities grew due to the Industrial Revolution. Recently, this connection between humans and Nature has become a significant field of study as researchers seek to further explore and explain this undeniable bond. A number of studies in environmental psychology have shown spending time in Nature can have physiological and psychological benefits including relieving stress and alleviating diagnosed psychological disor- ders (Berman et al., 2008, Berman et al., 2012, Ward Thompson, 2011, Wilson, 1984, Keniger et al., 2013, Logan and Selhub, 2012, Cervinka et al., 2012, MacKerron and Mourato, 2013, Gehl et al., 2006).

Despite long standing recognition and recent scientific evidence that the relationship between humans and Nature is beneficial and vital, there remains a lack of consideration for how this relationship interacts with architecture. Movements such as Organic Architecture recognise the need to integrate landscape with design, and Biomimicry takes design and technological inspiration from natural systems, but thus far architecture has tendency to approach the boundary between built and natural from an angle of aesthetics, with little research carried out on the influence Nature can have on a building's occupants. One study focussed in health care architecture discovered that a view of a natural environment reduced surgery recovery times (Raanaas et al., 2012); other studies have focussed on the benefits of introducing natural elements such as office plants to internal spaces (Brown and Bell, 2007); beyond this, the potential to utilize the innate human connection to Nature within architectural design is all but overlooked. With the world's global urban population already exceeding $50 \%$ and with this due to increase to $70 \%$ by 2050 (W.H.O., 2012), there is both a need 
to understand how Nature and architecture can coexist, and a potential for architects and planners to explore built environments which nourish humanity's seemingly biological need for proximity to Nature.

\section{Arcology and Arcosanti}

Arcology, a concept fusing architecture and ecology, was first proposed by architect Paolo Soleri in 1969, as the antithesis to the state of development of most modern US cities. Soleri saw the reliance on vehicular transport as generating massive urban sprawl and decentralisation away from the city centre to never ending suburbs. Soleri stated that these suburbs not only obliterated the ecology of the land they spread over, but that they also obliterated human connections and the ability for personal and collective growth. He proposed an alternative to this kind of living: an arcology would be a compact city, bringing people and services back to a centralised location, while the city would be tightly restricted in terms of horizontal growth thus leaving the surrounding natural environment untouched and in a state of wilderness. (Soleri, 1969, Soleri et al., 2011) In addition to providing a model for energy and resource efficiency, Soleri emphasised the potential for arcologies to provide a unique boundary between built and natural; "The structure of the habitat is intentionally putting nature at our fingertips" (Soleri, 1993); a point expanded upon by Grierson; "the drawing together of diverse city functions into mixed use, self-contained arcologies would encourage cultural intensification and social integration within their boundaries, while freeing up the surrounding hinterland to remain natural." (Grierson, 2003) In 1970, Soleri and a group of his students formed the Cosanti Foundation and began construction of Arcosanti, a new city presented as an "urban laboratory" and prototype arcology located in the high Sonoran desert of Arizona, USA. Arcosanti aims to explore high density, mixed use design built on a pedestrian scale, while leaving hundreds of acres of surrounding land as natural environment, allowing its residents to be both "city and country dwellers" (Soleri, 1993). At Arcosanti, the boundary between built and natural is immediate; a person can be in untouched

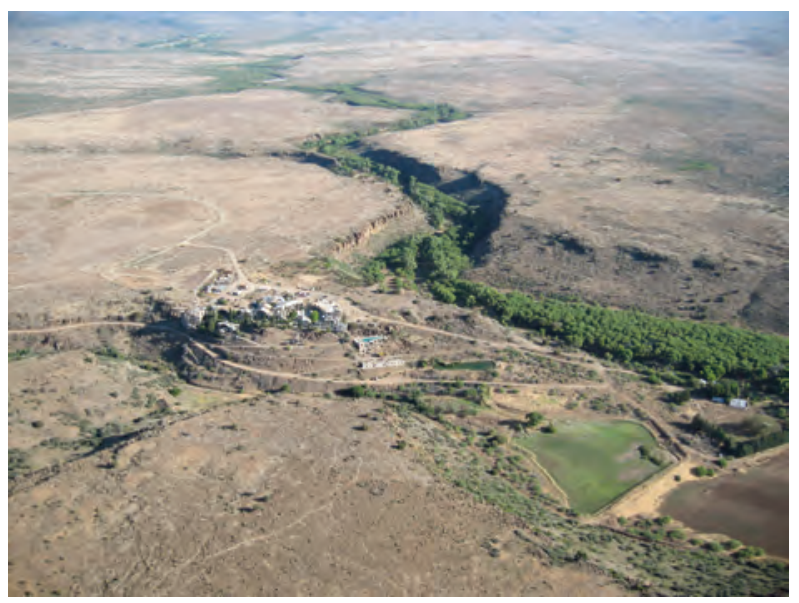

Figure 1.Aerial image of Arcosanti. (Source: Ernie Silva, May 15 2009).
Nature moments after leaving the density of the city. Soleri repeatedly stated that he could not, and would not, predict the social dynamic of an arcology: "What the project wants to avoid is planning the lives of its residents. They are offered a specific grid of environmental resources (the instrument) within which to act and play out their lives (the music)." (Soleri, 1993) Soleri believed that the social identity of an arcology would and should develop naturally, and the continved inhabitation of Arcosanti gives an opportunity for the social outcomes to be investigated. This work focusses on the effect this unique proximity to the natural environment has on activity within the built environment at Arcosanti.

Building on the proven cognitive impacts of Nature, this research work is interested in the resultant behavioural impact, specifically how the view of a natural environment from within a built social space affects social interaction within that space. Space Syntax has been used in architecture and urban design to analyse built forms and make empirically based design decisions on how spatial connectivity can influence social interactions. In this work, a Nature Syntax is being developed to explore if and how visual connectivity to Nature has this same influence. Does strong spatial connectivity affect social interactions more than visibility of Nature? Do users plan movement routes to include views of Nature, or do they focus on the fastest, most accessible routes regardless of view? Are users more likely to plan activities in the most easily accessed space, or does the view of Nature prove more influential in this decision? These are the types of questions this work is interested in exploring. Using Arcosanti as a development and testing ground, the work develops a Nature Syntax methodology to statistically quantify the naturalness of a view from within a built space - named in this study as the Visibility of Nature (VN) value. Space Syntax and Nature Syntax analysis for 15 social spaces at Arcosanti was completed, before onsite observations were carried out to document the usage patterns of each space. Correlations were then calculated, which suggest where relationships exist between spatial connectivity, Nature connectivity through visibility, and social interaction. It is proposed that the Space/Nature Syntax can be used to inform future design, firstly at Arcosanti then in other built environments, by using the correlations, relationships and patterns observed to predict how future design interventions could alter the existing spatial and natural connections and change interaction within an existing space. This paper details the development and initial application of this Space/Nature Syntax methodology, and outlines future steps in the work and future potential applications of the method for design.

\section{DEVELOPMENT OF SPACE/NATURE SYNTAX}

It is important to clarify what qualifies as a social space for the purpose of this study. The majority of buildings are Arcosanti are mixed use, containing spaces which are completely private (bedrooms, private living rooms), other spaces which are only open 


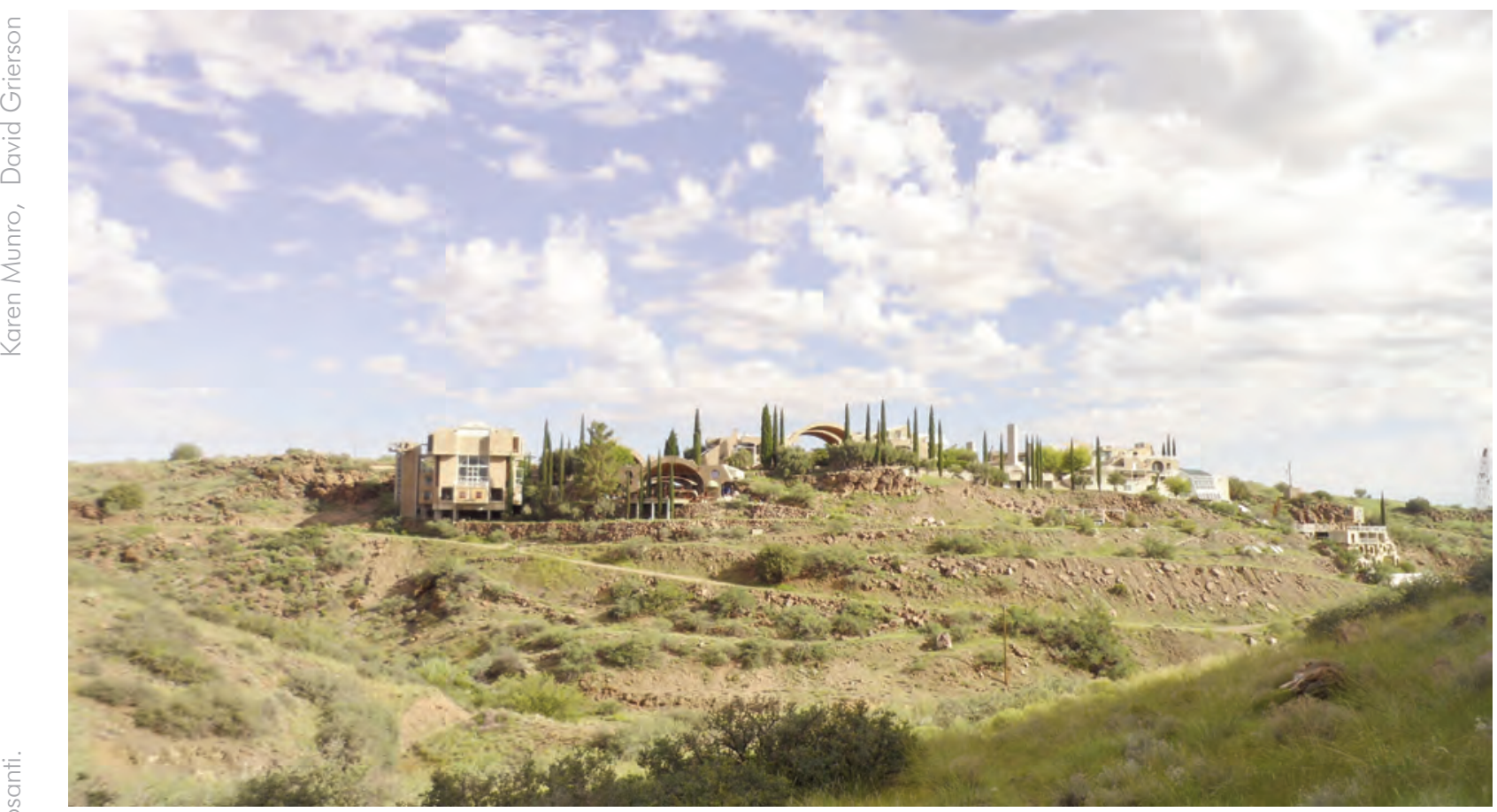

Figure 2. Arcosanti from the South. (Source: Author, September 13 2013).

within certain time parameters (public visitor centre) and others which are open and accessible for the use of Arcosanti residents at all times. Therefore, for the purpose of this study, a space is classed as a social space and analysed in the research if it is an interior or exterior space available for use by Arcosanti residents at any time of the day or night. There were 15 such spaces identified which were then analysed according to the methodology to be described in this paper.

\section{Space Syntax}

Space Syntax was introduced by Bill Hillier and Julienne Hanson and has been developed through numerous publications since 1976 (Hillier et al., 1976, Hillier and Hanson, 1984, Hillier, 1999, Hillier, 2007). Space Syntax is a method for the analysis of spatial configurations (Jeong and Ban, 2011) which gives statistical value to spaces within buildings and cities, allowing them to be analysed, adapted and planned. Space Syntax is commonly used to determine areas within individual buildings or the wider urban environment which have the potential for high social interaction (Campos and Fong, 2003) and has therefore been used in this study to analyse the social spaces at Arcosanti in order to determine which, at least according to spatial analysis, should be the most and least lively. There is a great deal of terminology associated with Space Syntax; those which are relative to this work are defined as thus:
- System - the building/area being studied; in this work, the Arcosanti site is th System. $N$ is used to represent the number of spaces in a System: $N=227$. Root Space - the space that is being analysed.

Depth (D) - the number of spaces between the Root Space and anothe space. A new Depth is reached when a threshold (an opening or junction) I crossed.

- Total Depth (TD) - the sum of all spaces at all Depths from the Root Space The Total Depth is calculated by multiplying the amount of spaces at eac Depth by the value of the Depth itself.

Mean Depth (MD) - the average Depth from the Root Space to all othe spaces in the System.

$M D=T D / N-1$

Connectivity (C) - a measure of the number of immediate spaces adjoinin the Root Space. The $C$ value is between 0 and 1 , with a higher numbe indicating fewer immediately adjoining spaces. It is achieved by dividing $1 \mathrm{~b}$ the number of spaces at one depth from the Root Space.

$c=1 /$

Integration/Integrated - a measure for the connections between the Roc Space and all other spaces within the System.

Relative Asymmetry (RA) - a measure of Integration for Systems c comparable size. The RA values describes the mean Depth of a space as fraction of the maximum possible Depth for that System (Bafna, 2003). R. values always range between 0 and 1 , where 0 is a strongly integrated spac and 1 is a weakly integrated space. in practice, an RA value of closer to would indicate a centrally located space.

$R A=2(M D-1) / N-2$

Real Relative Asymmetry (RRA) - a measure of Integration for Systems c drastically different sizes; as with the RA, the lower the RRA value, the mor accessible a space is. This is the key term used in this paper whe discussing spatial connectivity. The value is achieved by dividing the RA C the System by the average RA of a System of that size (Dk). A list of D the System by the average RA of a System of that size (Dk). A list of D is 0.047 . Unlike the $R A$ value, the RRA value can range above 1 ; spaces wit RRA figures from 0.4 to 0.6 are considered to have very strong integration i the System. (Bafna, 2003, Hillier and Hanson, 1984) The RRA allows System to be easily compared with any other regardless of size and wa other Space Syntax studies in future.

$R R A=R A / D_{k}$

Integration Value (IV) - the inverse of the RRA; therefore the higher the IV the more Integrated the space is and more likely to be a lively space. 
(Hillier and Hanson, 1984, Klarqvist, 1993, Jeong and Ban, 2011, Bafna, 2003)

\section{Nature Syntax}

This section will describe the development of the Nature Syntax method, which is being established through this research work. Nature Syntax analysis produces a value named the Visibility of Nature (VN) value, which is between 0 and 1 , where 0 is no visual connection to Nature and 1 is complete, $360^{\circ}$ visual connection to Nature. The VN value represents the ratio of the visibility of the natural environment out of the total external visibility from that space.

\section{Calculating the Permeability}

The first stage was to calculate how visually permeable each social space was. Permeability in the context of this paper refers to the area of building envelope of a space which is either open (e.g. an archway) or transparent (e.g. a window or skylight) - any opening through which the environment external to the space is visible. In order to calculate permeability, the area of building envelope which is permeable was calculated as a percentage of the total area. Internal drawings were produced of North, East, South, West, and Above for each social space, and sizes of openings and ceiling heights were verified on site at Arcosanti (Figure 3). The area of permeability in each of the 5 directions was then totalled and divided by the total surface area to achieve the percentage of total permeable surface area. This value was then divided by 100 to produce a figure between 0 and 1 , where 0 is a social space which is completely visually enclosed to its external environment, while 1 is a social space which is completely visually open to its external environment.

$$
\text { Permeability }=\frac{\left(\frac{\text { Total Permeable Surface Area }}{\text { Total Surface Area }}\right)}{100}
$$

\section{Calculating the Naturalness of View}

The next consideration was how to classify if a view was built, natural or somewhere in between. The solution was derived from the U.S. Geological Survey Land Cover Institute National Land Cover Database (NLCD) 2006, which documents land cover type according to well defined criteria, covering wide variants in both

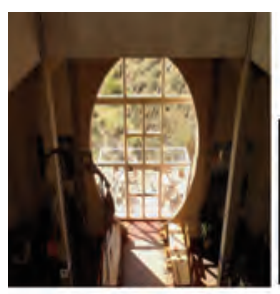

(a)

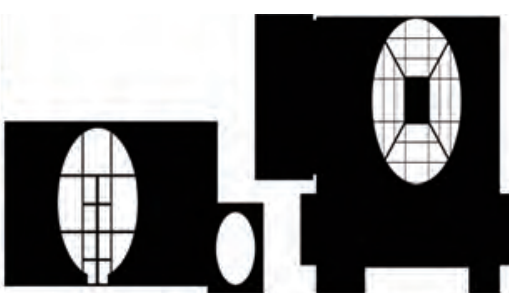

(c)
Figure 3. South façade of Arcosanti's Café (a); permeability diagrams for South façade (b) and Ceiling (c) where black indicates a solid area and white indicates a permeable area. The permeable and total areas were calculated using inbuilt AutoCAD tools to maximise accuracy. (Source: Author).

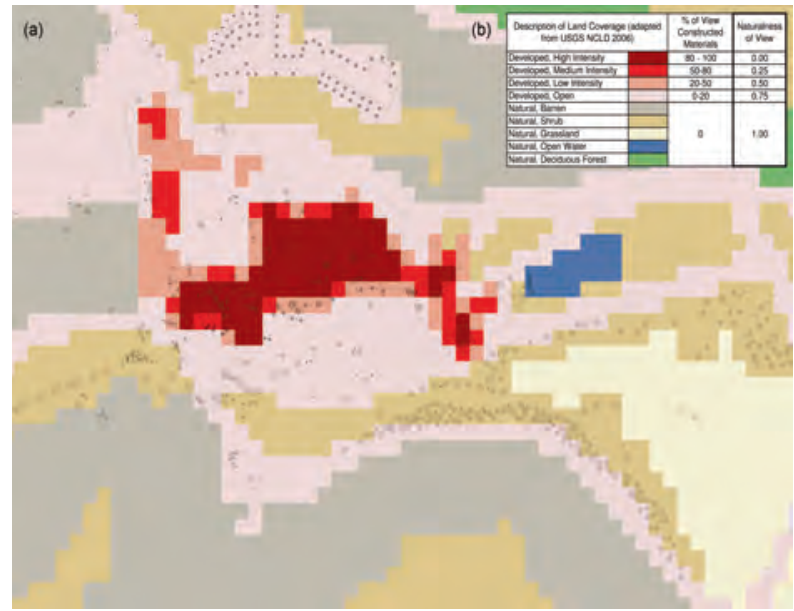

Figure 4. Arcosanti Land Cover Site Plan (a) and Land Cover Key (b) (Source: Author, derived from USGS LCI NLCD 2006 (US Department of the Interior and US Geological Survey, 2015, Anderson et al., 1976))

built and natural land cover (US Department of the Interior and US Geological Survey, 2015, Anderson et al., 1976). The NLCD 2006 consists of 20 categories of land cover, including 4 levels of built environment from "Developed, Open" to "Developed, High Intensity". The levels are defined by the percentage of material on an area of land which is constructed material. For the development of the Nature Syntax, the non-built categories of the NLCD were amalgamated into one "Natural" category, while the 4 built categories remained as defined in the NLCD. A plan of the Arcosanti site was overlaid with a $10 \mathrm{~m}^{2}$ grid which was then in-filled with the colour representing the relative land coverage; producing Figure 4a. Values between 0 and 1 were assigned to the 5 land cover classifications (Figure 4b). As "Natural" land coverage was the focus of the study, this classification was given a value of 1 , with "Developed, High Intensity" receiving a value of 0 , and the intermediate classifications given values in intervals of 0.25 .

In order to determine the Naturalness of View from each space, field of vision studies were carried out in both plan and section for each of the 15 social spaces. The foveal and peripheral fields of vision (based on (Gehl et al., 2006)) from a centre point in the space were drawn for each direction (North, East, South, West and Above) and overlaid onto the Land Cover plan in Figure 4, producing an image such as the example in Figure 5a. The type of land cover which was predominantly covered by the field of vision was taken to be the type of land cover most visible for that direction, and the associated value between 0 and 1 was documented. This process was then repeated in section for each space and direction to take into account the three-dimensionality of both the structures and Arcosanti site, and confirm the results found on plan (Figure 5b). Finally, the values documented were confirmed visually at the Arcosanti site by the researcher. The final value for Naturalness of View for each space is the sum of the value for the five directions, divided by 5 . 


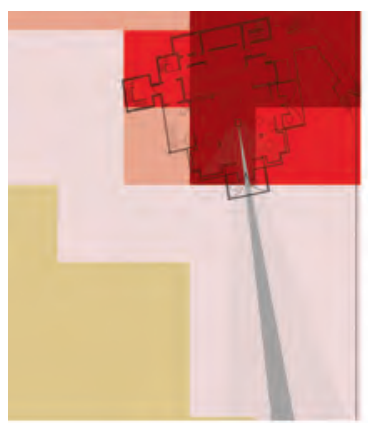

(a)

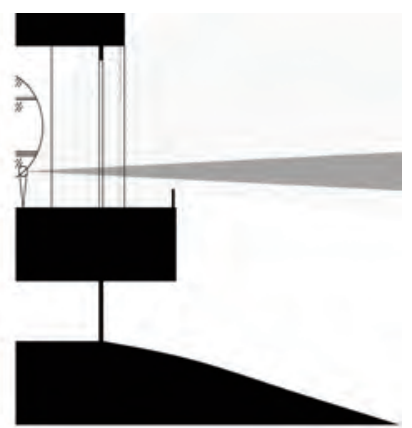

(b)
Figure 5. Field of Vision diagrams for Arcosanti Café's South façade in plan (a) and section (b) (Source: Author)

The final Visibility of Nature Values (VN) represents the ratio of total view from the space which is of the natural environment and is calculated as:

$$
\text { Visibility of Nature }(V N)=\left(\frac{\text { Naturalness of View }}{\text { Permeability }}\right) \times 100
$$

\section{Observation Studies}

With the Space Syntax and Nature Syntax analyses complete, the next step was to carry out observational studies on site at Arcosanti. The method was developed through background research into the observational methods commonly used in environmental psychology (Thwaites, 2007, Goli

nik and Ward Thompson, 2010, Costa, 2011, Gehl, 2011 , Gehl, 1987, Gehl, 2010, Liu and Sibley, 2004, Moirongo, 2002, Simpson, 2011, Zhang and Lawson, 2009). Over a 3 month period, from 17 February to 12 May 2015, each of the 15 social spaces at Arcosanti was repeatedly observed for 30 minutes at a time within 5 time frames: 0600-0900, 0900-1200, 1200-1500, 1500-1800, 1800-2100. A total of 107 observations were carried out, with the following behaviours being noted:

Type of Space Use

"Active" - space being directly used for an activity; space is the end destination.

"Inactive" - space being used inactively; as a through route to elsewhere.

Level of Planning

"Planned" - a predetermined activity taking place at an agreed time e.g. an arranged event; a work task; a meeting; a guided tour group.

"Unplanned" - a spontaneous activity undertaken e.g. a social interaction; informal/impromptu meeting; non-essential use as through route.

Visual Interaction with Natural Environment

A user observed displaying behaviour which facilitates a visual interaction with environment e.g. looking out window; positioning body towards natural environment; pointing; drawing; photographing.

The behaviours were noted, by hand, separately for each observation on a printed plan of the social space being analysed before data for each space was digitally compiled into one image, colour coded for time frames; examples of these resultant images will be seen in the next section of this paper.

\begin{tabular}{|l|r|r|r|r|r|r|}
\hline \multicolumn{1}{|c|}{ Social Space } & Total Depth & Mean Depth & Connectivity & RA & RRA & Integration Value \\
\hline & & & & & & \\
\hline Vaults & 1125 & 5.0 & 0.17 & 0.0354 & 0.7523 & 1.3292 \\
\hline Community Room & 1161 & 5.1 & 0.20 & 0.0368 & 0.7824 & 1.2780 \\
\hline Library/Rec Room & 1367 & 6.0 & 0.50 & 0.0449 & 0.9548 & 1.0473 \\
\hline Amphitheatre Seating & 1403 & 6.2 & 0.17 & 0.0463 & 0.9850 & 1.0153 \\
\hline Ceramics & 1519 & 6.7 & 0.33 & 0.0509 & 1.0820 & 0.9242 \\
\hline Sky Theatre & 1522 & 6.7 & 0.50 & 0.0510 & 1.0845 & 0.9220 \\
\hline Vauth Root & 1580 & 7.0 & 0.50 & 0.0533 & 1.1331 & 0.8826 \\
\hline Roof Patio & 1587 & 7.0 & 0.33 & 0.0535 & 1.1389 & 0.8780 \\
\hline Amphitheatre Stage & 1664 & 7.4 & 0.20 & 0.0566 & 1.2034 & 0.8310 \\
\hline Caté & 1676 & 7.4 & 0.20 & 0.0570 & 1.2134 & 0.8241 \\
\hline Music Centre & 1684 & 7.5 & 0.33 & 0.0573 & 1.2201 & 0.8196 \\
\hline EC Roof & 1771 & 7.8 & 1.00 & 0.0608 & 1.2929 & 0.7734 \\
\hline Classroom & 1828 & 8.1 & 1.00 & 0.0630 & 1.3406 & 0.7459 \\
\hline Red Room & 2063 & 9.1 & 0.33 & 0.0723 & 1.5373 & 0.6505 \\
\hline Oifice & 2103 & 9.3 & 0.25 & 0.0738 & 1.5707 & 0.6366 \\
\hline
\end{tabular}

Figure 6. Results of Space Syntax Analysis at Arcosanti, ordered from most spatially connected to least. (Source: Author).

\section{Correlation Analysis}

Finally, the results of the Space Syntax, Nature Syntax and observations studies were entered into the statistical analysis software Minitab, and Pearson correlations were calculated, which allowed an initial understanding of where the data is suggesting relationships between the variants.

\section{RESULTS OF SPACE/NATURE SYNTAX METHODOL- OGY IN USE AT ARCOSANTI}

The method was applied to the Arcosanti site, for the purpose of both initial testing of the current methodology and further development. Space Syntax analysis was completed off site using floor and site plans provided by the Cosanti Foundation, before being edited and verified on site by the researcher. The Space Syntax results for the Arcosanti site are displayed in full in Figure 6; the Vaults returned the lowest RRA thus suggesting it as the most central and connected space on site, while the Office returned the highest RRA.

Next, the VN value for each of the 15 social spaces was calculated by the process described in the previous section; the results can be seen in Figure 7. The space which returned the highest $\mathrm{VN}$ value and thus has the highest visual connection to Nature was the East Crescent Roof, while both the Community Room and Library/Rec Room had a VN value of 0 .

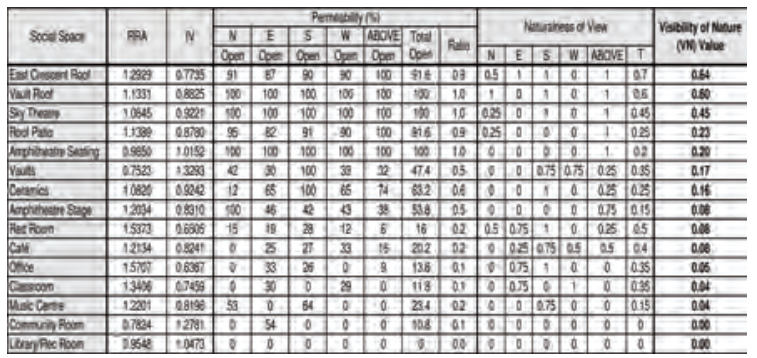

Figure 7. Results of Nature Syntax Analysis at Arcosanti, ordered from most visually connected to Nature to least. (Source: Author). 
The data from the observation studies of all 15 spaces was then compiled in order to investigate if this initial study at Arcosanti was suggesting existing relationships between RRA, VN, and social interaction. First, the usage patterns for the highest and lowest VN values were examined: the East Crescent Roof has the highest VN value, at 0.64 while the Community Room and Library/Rec Room both have VN values of 0 . The observed activity for the East Crescent Roof, Community Room and Library/Rec Room can be seen in Figure 8. Unsurprisingly, the East Crescent Roof had the highest proportion of people displaying a Visual Interaction with the Natural Environment, with $84 \%$ of all such interaction observed across all observations on all sites occurring on the East Crescent Roof. The Community Room and Library/Rec Room both had $0 \%$ of Visual Interaction with Natural Environment, again unsurprisingly as they have no visual relationship to Nature. There were marked differences in how the spaces were used; the East Crescent Roof was observed to have $18.7 \%$ of Total People over all observations, significantly higher than the Community Room (8.1\%) and the Library/Rec Room (0.8\%). The most interesting outcome from the observational data is that the East Crescent Roof experienced a completely different type of social interaction from both the Community Room and the Library/Rec Room. The East Crescent Roof saw 23.7\% of total Active use, and $0 \%$ of Inactive, compared to the Community Room which only saw $4.8 \%$ of Active Use, but $20.1 \%$ of Inactive use. The differences in social interaction were less significant for the Library/Rec

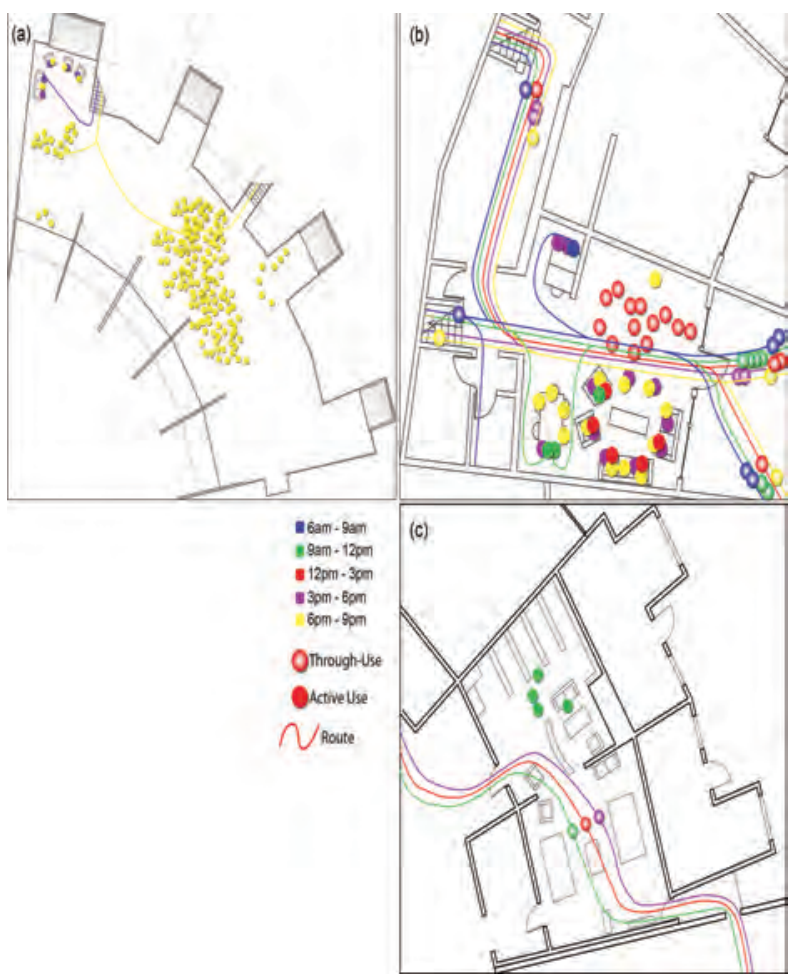

Figure 8.Social space usage pattern diagrams for the East Crescent Roof (a), Community Room (b) and Library/Rec Room (c), based on observations carried out at Arcosanti site in early 2015. (Source: Author).
Room, but were still greater for Inactive (1.6\%) than Active (0.6\%). Additionally, the East Crescent Roof was the location for a higher percentage of all Planned social interaction at $22.8 \%$ when compared to Unplanned Use at 2.8\%, again contrasting with the Community Room which had only $4.8 \%$ of Planned Use, but 20.6\% of Unplanned Use, and the Library/Rec Room which saw 0\% of Planned Use but 3.9\% of Unplanned Use.

The highest and lowest RRA values were then compared; these were for the Vaults (lowest RRA at 0.7523 ) and the Office (highest RRA at 1.5707). The observation study results for these spaces can be seen in Figure 9. According to the principles of Space Syntax, the Vaults should be a more lively and used space as they are more centrally located and accessible. However the observation studies found that the difference in activity in these spaces was not hugely significant when compared with the percentage differences for the highest and lowest values of the VN value; the Vaults had a $7.9 \%$ share of Total People, while the Office's share was 5\%. These slight differences are consistent throughout all categories of activity observed in the observation studies. The Vaults has only marginally more a percentage of total Active Use than the Office $(7.2 \%$ compared with $4.7 \%)$; total Inactive Use (10.9\% to 6\%); Planned Use $(7.8 \%$ to $5.7 \%)$; and Unplanned Use (8.3\% to $2.2 \%)$.

A brief analysis of the results of the Space Syntax, Nature Syntax and observations suggests a number of initial findings. The most significant of these is that there seems to be a relationship between visibility of a natural environment and how space is used. The East Crescent Roof, with the highest VN value appears to be a location for Active, Planned use

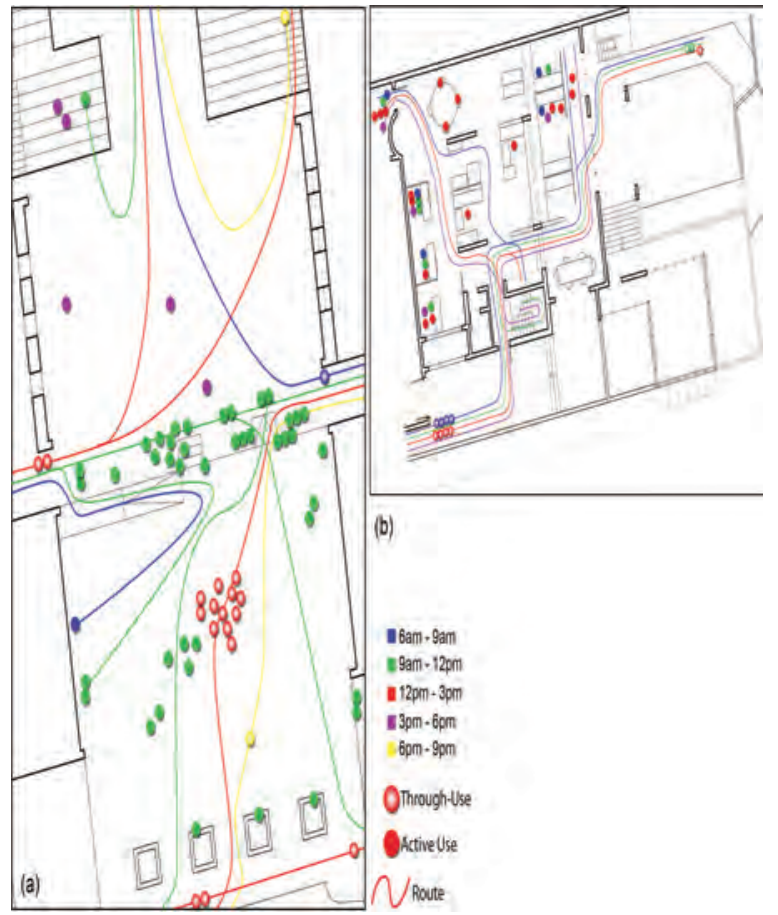

Figure 9. Constance Region based on the intensity of network connectivity. 


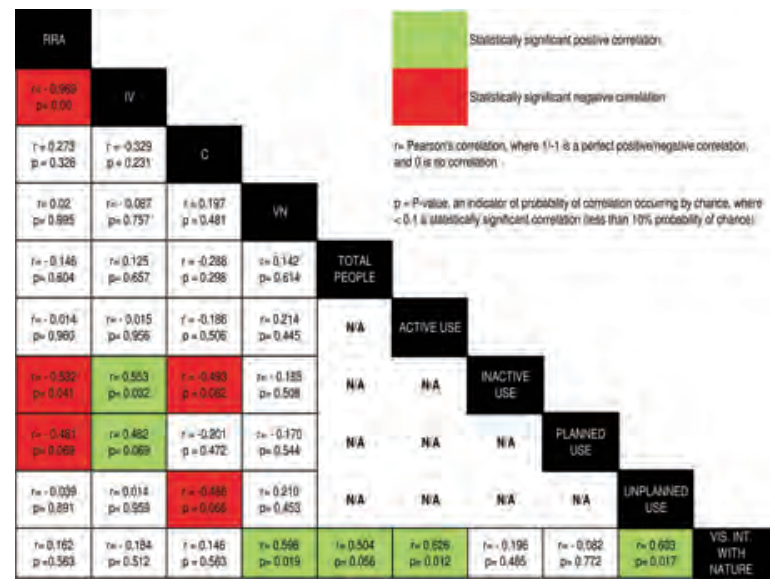

Figure 10. Constance Region based on the intensity of network connectivity.

while those with lowest $\mathrm{VN}$ values are used more for Inactive, Unplanned use. Another suggested finding is that, at the Arcosanti site at least, the spatial connectivity of a space does not influence its level of use as much as one might expect; the spaces which are at opposite end of the Space Syntax analysis results do not have as significant a distinction in use as those which are at the opposite ends of the Nature Syntax results, suggesting that the visibility of Nature from a social space does indeed play a role in how the space is used. While this paper only briefly discusses 5 of 15 spaces, these initial findings seem to be somewhat implied within the correlation data produced for all observations in the study. Figure 10 shows how there are significant correlations between RRA value, and Inactive Use and Unplanned Use. However, the correlations suggest relationships between $\mathrm{VN}$ value, and Active Use and Planned Use are less significant than the initial analysis of individual spaces implied. Finally, the correlation data seems to support the finding that the RRA value may not be as singularly influential in determining how a space is used as it would be expected, as the correlation between the two factors is not strong, as was also suggested in results of the observations.

The purpose of this paper was to present the development of the Space/Nature Syntax methodology within its academic context, and investigate its usefulness as a tool for determining how designing to maintain a human-Nature relationship can inform social interaction. The methodology takes into account both spatial connectivity and natural connectivity, through visibility of Nature, and its initial application at Arcosanti has produced both promising results and raised interesting issues for further investigation.

There are a number of future steps for this research work identified. Additional observational studies would strengthen and confirm the initial findings suggested in this paper, particularly with regards to the strength of the implied relationships between RRA and VN values, and types of social interaction; these additional observations have been carried out at

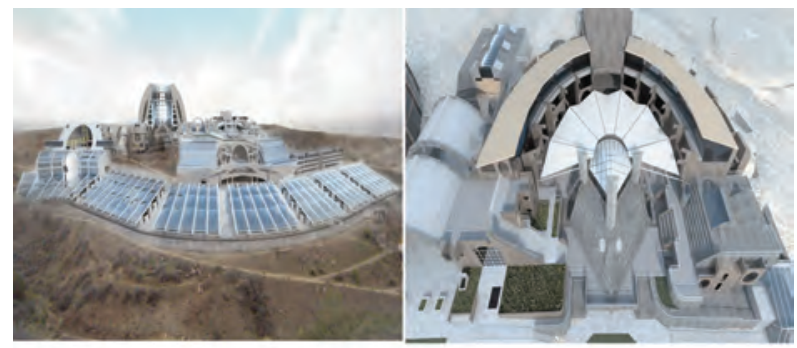

(a)

(b)

Figure 77. Constance Region based on the intensity of network connectivity.

the Arcosanti site during 2016 and initial analysis confirms the findings presented within this paper. The method will also be repeated for an existing theoretical next stage of development at the Arcosanti site; the completion of the East Crescent, which will see an additional floor being constructed as well as a theatre filling the currently vacant "Keystone" unit (Figure 11). The purpose of this is to explore, according to the correlation data for the existing site design, how future development at Arcosanti alters spatial connectivity and natural connectivity of the existing social spaces, and how these alterations could theoretically affect how social interaction in existing spaces. Finally, while the Space/Nature Syntax methodology has thus far been developed and tested solely on site at Arcosanti, it is intended to be a methodology which can be applied to any built environment. The possibility of applying the methodology to another site will be explored, which will assist in both the development of the methodology and ensuring its validity and relevance as a design and analysis tool.

There is a wealth of evidence to suggest that Wilson's Biophilia Hypothesis is indeed correct and the human-Nature relationship is innate, essential, and beneficial to us. There is an irrefutable connection between humans and the natural environment, one which has been shown to inspire, teach and help heal the human mind. However the migration from a rural civilisation to urban civilisation witnessed in recent human history continues at an ever increasing rate, and within 35 years the significant majority of the world's population will be urban dwellers. If the link between humans and Nature is accepted as essential, then the field of architecture, as the craftsman of the new human environment, has a significant role to play in creating built environments which nurture and maintain this relationship - arguably, they have a responsibility to do this. The development of the Space/Nature Syntax methodology aims to provide a tool which will help architects and designers to make informed design choices, and create built environments which both provide the benefits of city living that continue to attract so many people, while allowing the evolutionary connection with Nature to survive. 


\section{REFERENCES}

ANDerson, J. R., Hardy, E. E., ROACH, J. T. \& WitMer, R. E. (1976). A Land Use and Land Cover Classification System For Use With Remote Sensor Data. In: UNITED STATES DEPARTMENT OF THE INTERIOR (ed.). Washington: United States Government Printing Office.

BafNA, S. (2003). Space Syntax: A Brief Introduction to Its Logic and Analytical Techniques. Environment \& Behavior, 35, 17-29.

Berman, M. G., Jonides, J. \& Kaplan, S. (2008). The cognitive benefits of interacting with nature. Psychology Science, 19, 1207-12.

Berman, M. G., Kross, E., Krpan, K. M., Askren, M. K., Burson, A., Deldin, P. J., Kaplan, S., Sherdell, L., Gotlib, I. H. \& Jonides, J. (2012). Interacting with nature improves cognition and affect for individuals with depression. J Affect Disord, 140, 300-5.

BROWN, T. \& BELL, M. (2007). Off the couch and on the move: global public health and the medicalisation of nature. Social Science and Medicine, 64, 1343-54.

Campos, M. B. D. A. \& Fong, P. S. P. (2003). A proposed methodology to normalise total depth values when applying the visibility graph analysis. 4th International Space Syntax Symposium. London.

CervinkA, R., Roderer, K. \& Hefler, E. (2012). Are nature lovers happy? On various indicators of well-being and connectedness with nature. Journal of Health Psychology, 17, 379-88.

COSTA, M. (2011). Territorial Behavior in Public Settings. Environment and Behavior, 44, 713-721.

GeHL, J. (1987). Life between buildings : using public space, Copenhagen : Danish Architectural Press.

GeHL, J. (2010). Cities for people, Washington: Island Press.

GeHL, J. (2011). "Three Types of Outdoor Activities," "Life Between Buildings," and "Outdoor Activities and the Quality of Outdoor Space". In: LEGATES, R. T. \& STOUT, F. (eds.) The City Reader. 5th ed. New York: Routledge.

Gehl, J., Kaefer, L. J. \& Reigstad, S. (2006). Close encounters with buildings. URBAN DESIGN International, 11, 29-47.

GOLIČNIK, B. \& WARD THOMPSON, C. (2010). Emerging relationships between design and use of urban park spaces. Landscape and Urban Planning, 94, 38-53.

Grierson, D. (2003). Arcology and Arcosanti: Towards a Sustainable Built Environment. Electronic Green Journal, 1.

GrInDE, B. \& PATIL, G. G. (2009). Biophilia: does visual contact with nature impact on health and well-being? International Journal of Environmental Research and Public Health, 6, 2332-43.

HILLIER, B. (1999). The hidden geometry of deformed grids: or, why space syntax works, when it looks as though it shouldn't. Environment and Planning B: Planning and Design, 26, 169-191.

Hillier, B. (2007). Space is the Machine. Space Syntax at University College London.

Hillier, B. \& Hanson, J. (1984). The social logic of space, Cambridge, London, Cambridge University Press.

Hillier, B., Leaman, A. \& Bedford, M. (1976). Space Syntax. Environment and Planning B: Planning and Design, 3, 147-185.

JeONG, S. K. \& BAN, Y. U. (2011). Computational algorithms to evalvate design solutions using Space Syntax. Computer-Aided Design, 43, 664-676.

Keniger, L. E., Gaston, K. J., Irvine, K. N. \& Fuller, R. A. (2013).
What are the benefits of interacting with nature? International Journal of Environmental Research and Public Health, 10, 913-35.

KLARQVIST, B. (1993). A Space Syntax Glossary. Nordic Journal of Architectural Research, 2, 11-12.

LIU, J. H. \& Sibley, C. G. (2004). Attitudes and behavior in social space: Public good interventions based on shared representations and environmental influences. Journal of Environmental Psychology, $24,373-384$

Logan, A. C. \& Selhub, E. M. (2012). Vis Medicatrix naturae: does nature "minister to the mind"? Biopsychosoc Med, 6, 11.

MacKerRon, G. \& Mourato, S. (2013). Happiness is greater in natural environments. Global Environmental Change, 23, 992-1000.

MoIrongo, B. O. (2002). Urban public space patterns: human distribution and the design of sustainable city centres with reference to Nairobi CBD. URBAN DESIGN International, 7, 205-216.

RaAnaAs, R. K., Patil, G. G. \& Hartig, T. (2012). Health benefits of a view of nature through the window: a quasi-experimental study of patients in a residential rehabilitation center. Clin Rehabil, 26, 21 32.

SIMPSON, P. (2011). Street Performance and the City: Public Space, Sociality, and Intervening in the Everyday. Space and Culture, 14, 415-430.

SOlerl, P. (1969). Arcology: the city in the image of man, Cambridge, Mass. : MIT Press.

SOlerl, P. (1993). Arcosanti : an urban laboratory?, Mayer, AZ : Cosanti Press.

Soleri, P., Kim, Y., Anderson, C., Nordfors, A., Riley, S. \& Tamura, T. (2011). Lean Linear City: Arterial Arcology, Mayer, AZ, Cosanti Press.

THWAITES, K. (2007). Urban sustainability through environmental design : approaches to time, people, and place responsive urban spaces, New York : Routledge.

US Department of the Interior \& US Geological SuRvey. (2015). National Land Cover Database 2006 (NLCD 2006) [Online]. Available: http://www.mrlc.gov/nlcd2006.php [Accessed 12 December 2014].

W.H.O. (2012). Urban Population Growth [Online]. Available: http://www.who.int/gho/urban_health/situation_trends/urban_population growth text/en/ [Accessed 28th September 2013].

Ward Thompson, C. (2011). Linking landscape and health: The recurring theme. Landscape and Urban Planning, 99, 187-195.

WILSON, E. O. (1984). Biophilia, Harvard University Press.

YOUNGSOO KIM \& COSANTI FOUNDATION (2009). East Crescent Completed.

Zhang, W. \& LAWSON, G. (2009). Meeting and greeting: Activities in public outdoor spaces outside high-density urban residential communities. URBAN DESIGN International, 14, 207-214.

\section{Author(s):}

\section{Karen Munro}

Department of Architecture, University of Strathclyde Email:karen.munro@strath.ac.uk

\section{Dr David Grierson}

Department of ArchitectureUniversity of Strathclyde

Email: d.grierson@strath.ac.uk 